\title{
Core point-of-care ultrasound curriculum: What does every anesthesiologist need to know?
}

\section{Les apprentissages fondamentaux de l'échographie au point d'intervention: ce que chaque anesthésiologiste a besoin de savoir}

\author{
Massimiliano Meineri, MD, FASE (D) - Gregory L. Bryson, MD • Ramiro Arellano, MD • \\ Nikolaos Skubas, MD, FASE
}

Received: 27 October 2017/Revised: 18 December 2017/Accepted: 18 December 2017/Published online: 16 January 2018

(C) Canadian Anesthesiologists' Society 2018

\begin{abstract}
Point-of-care ultrasound (POCUS) is becoming an integral part of anesthesia practice throughout the world. Despite the growing interest in POCUS among trainees and faculty, POCUS training is variable among universities across Canada. This suggests a need for curriculum development and standardization. International guidelines for Emergency Medicine and Critical Care have common frameworks and may be used as a reference to model anesthesia-specific curricula. The Royal College of Anaesthetists of the United Kingdom currently offers the only nationally approved POCUS curriculum for anesthesia and critical care trainees. Most curricula have in common a stepwise approach that consists of foundation of knowledge and skills and competency building through practice. Nevertheless, a significant variety of didactic modalities have been described, and online learning and simulation offer clear advantages. What constitutes the minimum number of studies necessary to achieve
\end{abstract}

\footnotetext{
M. Meineri, MD, FASE ( $\square)$

Department of Anesthesia and Pain Management, Toronto

General Hospital, University Health Network, University of

Toronto, 200 Elizabeth Street EN3-400, Toronto, ON M5G 2C4,

Canada

e-mail: massimiliano.meineri@uhn.ca
}

G. L. Bryson, MD

Department of Anesthesiology and Pain Medicine, University of Ottawa, Ottawa, ON, Canada

R. Arellano, MD

Department of Anesthesia, University of Western Ontario, London, ON, Canada

N. Skubas, MD, FASE

Department of Cardiothoracic Anesthesiology, Cleveland Clinic Foundation, Cleveland, OH, USA competence is still debated as are the most appropriate tools for assessment of POCUS competency.

Availability of trained staff anesthesiologists remains a major limitation to curricula implementation in most centres. A National Curriculum should be modeled on the Competency By Design Approach, in line with the CanMEDS 2015 roles, and start with a focus on basic POCUS modalities and applications. Guidance for the training and certification of POCUS among practicing anesthesiologists is lacking.

Résumé L'échographie au point d'intervention (PoCUS) est en train de devenir une partie intégrante de la pratique de l'anesthésie dans le monde entier. Malgré l'intérêt croissant pour l'échographie PoCUS parmi les étudiants et le corps professoral, la formation varie entre les universités canadiennes. Cela suggère le besoin d'élaborer et de standardiser les programmes de formation. Les lignes directrices internationales pour la médecine d'urgence et les soins intensifs partagent des cadres communs et peuvent servir de référence à un modèle de programme de formation propre à l'anesthésie. $A u$ Royaume-Uni, le Royal College of Anaesthetists propose actuellement le seul programme d'étude de l'échographie PoCUS qui soit approuvé au niveau national pour les stagiaires en anesthésiologie et en soins intensifs. La majorité des programmes comporte une approche progressive consistant en connaissances de base et en habiletés et compétences acquises avec la pratique. Toutefois, plusieurs modalités didactiques ont été décrites : l'apprentissage en ligne et la simulation offrant des avantages évidents. Ce qui constitue le nombre minimum d'études nécessaire pour devenir compétent reste un sujet de discussion, de même que les outils les 
plus adaptés pour l'évaluation de la compétence dans le domaine de l'échographie PoCUS.

La disponibilité d'anesthésiologistes formés reste une limite majeure à la mise en ouvre des programmes de formation dans la plupart des centres. Un programme d'études national doit être modelé sur la démarche de Compétence par conception (CPC) conforme aux rôles du CanMEDS 2015 et commencer en se concentrant sur les modalités et applications de base de l'échographie PoCUS. Il manque un soutien pour la formation et la certification des anesthésiologistes en activité à la pratique de l'échographie PoCUS.

Point-of-care ultrasound (POCUS) offers the anaesthesiologist a suite of bedside tools to answer specific questions in daily perioperative medicine practice, narrow differential diagnoses, and improve the safety of routine procedures. ${ }^{1-8}$ Ultrasound technology made its way into anesthesia practice almost two decades ago when it was implemented as procedural guidance for regional anesthesia ${ }^{9}$ and vascular access. ${ }^{10}$ At the same time, intraoperative transesophageal echocardiography became an indispensable tool for anesthesiologists in the cardiac operating room. ${ }^{11,12}$ The evidence base for basic transesophageal ${ }^{13}$ and transthoracic echocardiography in non-cardiac surgery ${ }^{14}$ has been increasing in time with the demand for training in these skills. A recent survey of Canadian academic departments of anesthesiology ${ }^{15}$ reported that 13 of $17(76 \%)$ of the programs surveyed had some focused, POCUS training as part of their residency training; 12 of 17 (70\%) believed it should be part of the anesthesia residency curriculum. A key challenge faced by any program wishing to introduce POCUS training is "What are we going to teach?"

In a recent "call to action", Mahmood et al. ${ }^{16}$ suggested 25 diagnostic and 19 procedural uses of ultrasound. Their list (Table 1) ranges broadly in scope from assessment of fluid status to confirmation of correct placement of a urinary catheter. Clinicians will undoubtedly argue the relative merits of the different systems evaluated by ultrasound and how each fits in a POCUS curriculum. Indeed, a recent survey of Canadian anesthesia residency program directors ${ }^{15}$ found significant disagreement on the techniques to be acquired during residency training. The majority of responders considered venous and arterial access, peripheral and neuraxial blocks, lung ultrasound, transthoracic echocardiography, and assessment of the inferior vena cava as "important" or "very important". These only include cardiac and lung ultrasound as diagnostic applications. Other POCUS applications of specific interest to anesthesiologists such as regional anesthesia, airway, and gastric assessment were not considered of primary interest.
The purpose of this narrative review is to identify the POCUS applications relevant to anesthesiology and perioperative medicine. We will begin with a broad evaluation of POCUS training standards from other kindred specialties such as emergency medicine and critical care and then narrow our focus to anesthesiologyspecific training standards in use elsewhere. Where possible, we will cast our descriptions in the language of skill levels and specific applications and conclude with future challenges that must include continuing professional development.

\section{Point-of-care ultrasound outside the operating room}

Emergency medicine has pioneered the introduction of POCUS in clinical practice and includes ultrasound as a learning objective in its Canadian postgraduate curricula. The International Federation of Emergency Medicine (IFEM) released a consensus document to guide development of POCUS training programs in Emergency Medicine around the world. ${ }^{17}$ Their proposed framework is, however, very generic and seems to fulfill the needs of different specialties for a variety of clinical, infrastructure, and logistical demands (Fig. 1). According to this guide, curriculum development involves first definition of practice and, in parallel, development of the methodology of training for each POCUS application. The definition of practice requires identification of core and advanced (enhanced) ultrasound application; of these, some are diagnostic and some procedural. The methodology of training is then structured in four steps: introduction to the application, development of experience, achievement of competence, and maintenance of competence.

The Canadian recommendations for critical care ultrasound training and competency are aimed at all Canadian critical care providers and describe a framework for training and a pathway to achieving competency. ${ }^{18}$ They are largely based on the American College of Chest Physician statement for critical care ultrasonography ${ }^{19}$ and the International Expert Statement on Training Standard for Critical Care. ${ }^{20}$ Specific ultrasound applications are divided into basic and optional (Table 2). The framework for training defines the minimum requirements for a centre to maintain a training program and training supervisors named "local experts". Similarly to what was described for emergency medicine, the training pathway consists of four steps: introductory training (course/workshop based), portfolio completion (acquisition of case log), competency assessment (review of $\log$ and skills assessment) and quality assurance, and maintenance of competence (continuing education and case review). 
Table 1 Ultrasound applications relevant to anesthesiology and perioperative medicine

\begin{tabular}{|c|c|}
\hline Target & Applications \\
\hline Eye & $\begin{array}{l}\text { Diagnostic: } \\
\text { Optic nerve sheath to estimate intracranial } \\
\quad \text { pressure } \\
\text { Retinal detachment } \\
\text { Vitreous hemorrhage } \\
\text { Lens dislocation } \\
\text { Retrobulbar hematoma } \\
\text { Foreign bodies }\end{array}$ \\
\hline Airway & $\begin{array}{l}\text { Diagnostic: } \\
\text { Vocal chord mobility } \\
\text { Neck fat tissue } \\
\text { Diaphragmatic movement } \\
\text { Cervical spine } \\
\text { Predict extubation failure } \\
\text { Procedural } \\
\text { Upper airway regional block } \\
\text { Cricoid membrane puncture and } \\
\text { cricothyroidotomy } \\
\text { Detection of endotracheal intubation } \\
\text { Tracheostomy } \\
\text { Detection of double lumen tube placement }\end{array}$ \\
\hline Vascular & $\begin{array}{l}\text { Diagnostic: } \\
\text { Aortic dissection } \\
\text { Carotid artery } \\
\text { Procedural: } \\
\text { Central venous and arterial access } \\
\text { Peripheral venous and arterial access }\end{array}$ \\
\hline Lungs & $\begin{array}{l}\text { Diagnostic: } \\
\text { Dyspnea } \\
\text { Pneumothorax } \\
\text { Pulmonary edema } \\
\text { Pleural effusion } \\
\text { Pneumonia } \\
\text { Procedural: } \\
\text { Thoracenthesis }\end{array}$ \\
\hline Cardiac & $\begin{array}{l}\text { Diagnostic: } \\
\text { Echocardiography } \\
\text { Hemodynamic evaluation } \\
\text { Fluid status assessment } \\
\text { Procedural: } \\
\text { Pericardiocanthesis } \\
\text { Detection of pacing capture }\end{array}$ \\
\hline Abdominal & $\begin{array}{l}\text { Diagnostic: } \\
\text { Determination of gastric content and volume } \\
\text { Detection of abdominal free fluid (FAST) }\end{array}$ \\
\hline
\end{tabular}

Table 1 continued

\begin{tabular}{|c|c|}
\hline Target & Applications \\
\hline $\begin{array}{l}\text { Regional } \\
\text { anesthesia }\end{array}$ & $\begin{array}{l}\text { Procedural: } \\
\text { Peripheral nerve blocks } \\
\text { Neuraxial blocks } \\
\text { Trunk blocks }\end{array}$ \\
\hline Other procedures & $\begin{array}{l}\text { Procedural: } \\
\text { Confirmation of Foley catheter insertion } \\
\text { Abscess drainage }\end{array}$ \\
\hline
\end{tabular}

FAST $=$ focused assessment with sonography in trauma

Modified from: Mahmood F, Matyal R, Skubas N, et al. Perioperative ultrasound training in anesthesiology: a call to action. Anesth Analg 2016; $122: 1794-804^{16}$

\section{Point-of-care ultrasound for anesthesiologists}

There is no current consensus on what perioperative POCUS comprises and no national curriculum in Canada. The only published national ultrasound curriculum is from the Association of Anaesthetists of Great Britain and Ireland and the Intensive Care Society. ${ }^{21}$ The curriculum is directed, without distinctions, to both anesthesia and intensive care trainees and serves as a guide to future full integration of POCUS training into the Royal College of Anaesthetists (RCoA) residency training.

The Curriculum defines three levels of competency: level 1(core), level 2 (extended), and level 3 (advanced). Level 1 includes generic competences that should be achieved during standard postgraduate specialist training while level 3 is comparable to specialist training of cardiology and radiology.

The guideline defines basic essential elements of knowledge and skills that represent the foundation of any level of competence and are included in a detailed ultrasound competencies list on the following areas: basics of ultrasound, administration, interpersonal communication, scanning, and needle-guidance technique. These are followed by a list of knowledge and practice skills including the minimum pathology variation for each POCUS application. An example of the detailed checklist for vascular access is shown in Fig. 2.

As in Canada, the United States has no formal POCUS curriculum for anesthesiologists but several local programs have been well described. Ramsingh et $a .^{22}$ described the Focused PeriOperative Risk Evaluation Sonography Involving Gastro-Abdominal Hemodynamic and Transthoracic ultrasound (FORESIGHT) comprehensive perioperative POCUS curriculum. While not adopted nationally, the curriculum developed and implanted at the University of California Irvine was based on six clinical Accreditation Council for Graduate Medical Education 
Fig. 1 Framework for point-ofcare ultrasound curriculum development by the International Federation of Emergency Medicine

\section{IFEM Point-of-Care Ultrasound (PoCUS)}

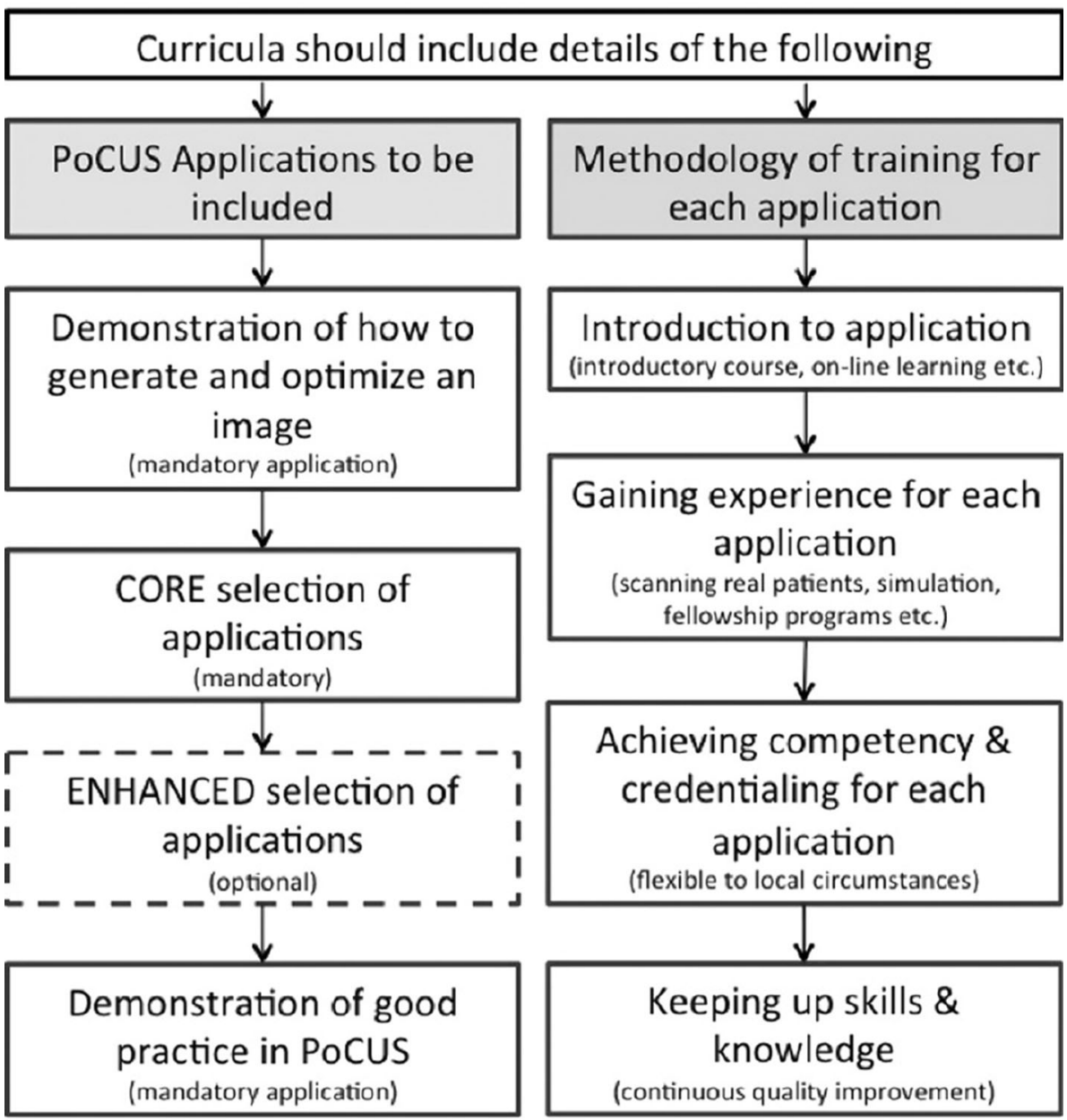

(ACGME) core competencies for anesthesiology. The curriculum includes echocardiography, lung, abdominal, airway, optic nerve sheath ultrasound, and vascular access. Specific objectives were defined for each application. The curriculum was delivered over a two-year period. The initial basic training consisted of a weekly 20 -min lecture followed by a 25 -min human model or simulation practice delivered over a six-month period. Simulation training included specific ten-minute scenarios on key components of each of the POCUS applications included in the curriculum. This was followed by supervised hands-on training. As part of an evaluation of the curriculum, 
Table 2 Summary of national and local POCUS curricula

\begin{tabular}{|c|c|c|c|c|c|}
\hline Organization & Levels & Course structure & $\begin{array}{l}\text { Training } \\
\text { duration }\end{array}$ & $\begin{array}{l}\text { POCUS } \\
\text { applications }\end{array}$ & $\begin{array}{l}\text { Competence } \\
\text { assessment }\end{array}$ \\
\hline Royal College of Anaesthetists ${ }^{21}$ & $\begin{array}{l}\text { Level 1: basic } \\
\text { Level 2: } \\
\quad \text { extended } \\
\text { Level 3: } \\
\quad \text { advanced }\end{array}$ & $\begin{array}{l}\text { Basic course supervised } \\
\text { practice }\end{array}$ & 12 months & $\begin{array}{l}\text { Regional } \\
\quad \text { Anesthesia } \\
\text { Vascular Access } \\
\text { Lung Ultrasound } \\
\text { TTE } \\
\text { FAST } \\
\text { IVC Assessment }\end{array}$ & Checklists \\
\hline $\begin{array}{l}\text { University of California at } \\
\text { Irwine }^{22}\end{array}$ & One level & $\begin{array}{l}\text { Basic course supervised } \\
\text { practice }\end{array}$ & 24 months & $\begin{array}{l}\text { Optic nerve sheath } \\
\text { Airway } \\
\text { Lung } \\
\text { TTE } \\
\text { Vascular access } \\
\text { Gastric } \\
\text { FAST }\end{array}$ & $\begin{array}{l}\text { Direct observation } \\
\text { MCQ }\end{array}$ \\
\hline Harvard Medical School ${ }^{23}$ & One level & $\begin{array}{l}\text { Basic course supervised } \\
\text { practice }\end{array}$ & 13 weeks & $\begin{array}{l}\text { Vascular Access } \\
\text { Regional } \\
\quad \text { Anesthesia } \\
\text { Lung Ultrasound } \\
\text { TTE } \\
\text { TEE } \\
\text { FAST }\end{array}$ & $\begin{array}{l}\text { MCQ } \\
\text { checklist }\end{array}$ \\
\hline
\end{tabular}

FAST = fast abdominal scanning in trauma; IVC = inferior vena cava; MCQ = multiple choice questions; TEE = transesophageal echocardiography; TTE $=$ transthoracic echocardiography

Fig. 2 Example of assessment checklist from the Royal College of Anaesthetists of the United Kingdom ${ }^{31}$

\section{Assessment checklist - vascular procedures}

\begin{tabular}{|l|}
\hline Demonstration of appropriate attitude and professional manner \\
\hline Explanation of procedure, risks and complications to patient as appropriate \\
\hline Checking patient's details/entry into machine as appropriate \\
\hline Confirmation of indication and checking of any supportive imaging \\
\hline Positioning of patient and machine ergonomically \\
\hline Selection of appropriate probe and optimisation of machine settings \\
\hline Identification of the vein and artery in transverse and longitudinal scan \\
\hline Confirmation of patency and absence of thrombus or haematoma by compression, \\
Doppler \\
\hline Undertaking of ultrasound guided cannulation in real time maintaining sterility \\
\hline Identification of needle tip using in-plane or out-of-plane technique \\
\hline Identification of guide wire within vein \\
\hline Insertion of appropriate sized cannula into vessel to correct length and secure \\
\hline Performance of technique safely and effectively \\
\hline Attention to sterility with respect to procedure, patient and machine \\
\hline Adequate documentation and storage of images and scans as appropriate \\
\hline Provision of information to patient and reporting of findings where appropriate \\
\hline Identification of whether a further scan or alternative imaging is indicated \\
\hline Cleaning of equipment and storage to minimise damage \\
\hline
\end{tabular}


students were randomly allocated to receive pathology training in their second year. Knowledge was assessed at various time points using standard multiple-choice questions. Point-of-care ultrasound competence was assessed on real clinical scenarios; residents who received pathology training showed a higher level of competence.

Another successful local model was proposed by the group from Harvard $^{23}$ that included a multimodal curriculum combining didactic modalities with on-line learning, simulators, live model scanning, and case-based discussions. The curriculum was structured to provide an introduction to basic knowledge, opportunities to build a portfolio, and a final evaluation. The basic knowledge was delivered over 13 days and included the following POCUS applications: vascular access, regional anesthesia, transthoracic and transesophageal echocardiography, lung, and focused assessment with sonography in trauma (FAST) abdominal scanning. A set number of scans was defined for each modality and the final assessment was based on a detailed checklist. None of the anesthesia-specific programs cited, however, include maintenance of competence as per IFEM and Canadian Critical Care ultrasound frameworks.

\section{Curriculum delivery}

If we are to incorporate POCUS training on a national scale in Canada, we must prepare to train both students and their faculty. The published POCUS curricula and guidelines in anesthesiology training share a similar structure of basic ultrasound knowledge building followed by manual skill development for image acquisition and procedures. These two initial steps are followed by need for practice and portfolio building. Many teaching models have been proposed in POCUS training and vary from hands-on training on patients to self-learning models and simulations. ${ }^{8}$ A systematic approach to POCUS training was proposed in the I-AIM framework that theorizes a stepwise approach to POCUS competency through the acquisition of fundaments of Indication, Acquisition, Interpretation, and clinical decision-Making.

Available guidelines on POCUS curriculum development do not mandate a specific didactic strategy and allow individual organizations to rely on their available resources. A Canadian university has reported on the feasibility and user satisfaction of a compact POCUS training course within its residency training program. ${ }^{24}$ The curriculum consisted of four weekly two-hour theoretical sessions followed by an hour of hands-on scanning. The study proved the feasibility of curriculum delivery but was limited by the impact assessment, based on pre-post course test knowledge improvement, and a curriculum limited to cardiac scanning.

Despite their initial high cost, the use of simulators has proven very efficient in shortening training time and speeding up the learning curve. ${ }^{25,26}$ For this reason, their use may have an even stronger role in the training of practicing anesthesiologists. Similarly online resources ${ }^{27,28}$ allow continuous learning "on demand", fit the needs of newer generations of learners, and allow for a "flipped" classroom model.

\section{Challenges to establishing Canadian POCUS training}

Lack of trained anesthesia staff is still considered a primary limitation to the introduction of POCUS in anesthesia residency curricula. Although over $75 \%$ of Canadian anesthesiology training programs include some element of POCUS in their training, only $25 \%$ of faculty were using focused cardiac ultrasound in their daily practice. ${ }^{15}$

Surprisingly, only 177 of 379 (46\%) surveyed members of the Society of Cardiovascular Anesthesiologists practice cardiac ultrasound on a daily basis and 152 of 379 (40\%) were comfortable teaching it. ${ }^{29}$ This concentration of expertise greatly limits opportunities for bedside instruction, assessment of competence, and integration of the technical and cognitive aspects of scanning. Rapidly creating a pool of practicing anesthesiologists capable of mentoring trainees, or one another, presents a formidable challenge.

The RCoA included in their guidelines training of anesthesia staff as a specific clinical pathway to mitigate some specific challenges such as access to supervision and feedback. Nevertheless, the overall curriculum is structured in parallel to the trainee pathway described above and shares the same content. A recent report described the successful introduction of POCUS training among staff in a university anesthesia department for pre- and intra-hospital acute care. ${ }^{30}$ The curriculum included basic heart and lung scanning and was delivered in a flipped classroom mode where the staff enrolled had to complete a set of e-learning modules prior to attending a one-day hands-on course followed by one day of supervised scanning. After this introduction staff were left to unrestricted practice and tested at different time points on healthy volunteers. All study participants showed good skills and long-term retention of knowledge. Time allocated to POCUS practice, difficulty in image acquisition, lack of knowledge, and scant evidence for some applications specific to perioperative care were identified as limiting factors to the introduction of POCUS among anesthesiology staff in the perioperative setting. 
Table 3 Specific POCUS objectives for anesthesia training in CanMED format

\section{Medical Expert}

Ultrasound Physics, Cardiorespiratory Anatomy \& Physiology The resident is expected to:

- Understand basic ultrasound physics and artefacts

- Describe the relevant sono-anatomy of the heart, lung, pleura, and abdominal structures

- Discuss the important aspects of cardiac and respiratory physiology that relate to normal ultrasound findings

Perioperative Diagnostic Ultrasound

The resident will be able to:

- Describe the indications and limitations of point-of-care ultrasound as a perioperative diagnostic modality

- Select the correct settings and appropriate probe for ultrasound examination

- Obtain focused cardiac ultrasound views, perform a basic 4-point lung and pleural ultrasound examination, use ultrasound to assess gastric contents, and determine the presence of free fluid in the abdomen

Understand the basic concepts, limitations, and potential applications of M-mode, pulse-wave, continuous-wave, and color flow Doppler, in answering specific clinical questions in the perioperative setting

- Appreciate the impact of ultrasound findings in altering perioperative patient management

- Identify specific sonographic features of conditions that might contribute to cardiorespiratory failure (hypovolemia, distributive shock, left ventricular/right ventricular failure, significant valvulopathies, pericardial/pleural effusions, pulmonary edema, lung consolidation, and pneumothorax)

- Confirmation of endotracheal intubation, identification of the cricothyroid membrane, and performing deep venous thrombosis ultrasound assessments are optional, and not considered core elements of this rotation

\section{Communicator}

Effective communication skills will be discussed, encouraged, and expected at several levels

A. Between the resident and the attending perioperative point-of-care ultrasound consultant: $\bullet$ For each case, the resident will discuss the ultrasound findings, clinical context, and possible implications for perioperative patient management with their attending consultant

B. Between the resident and the patient:

- The resident will discuss the indications for ultrasound examination and obtain informed consent. The resident will also obtain patient consent for scans being done solely for educational purposes. If unexpected abnormalities are encountered, the resident will inform the patient after reviewing with the findings with the consultant

C. Between the resident and the surgical and anesthesia teams:

- When appropriate, the resident will provide a brief report to the surgical and anesthesia teams involved in perioperative patient care. After consulting with the attending, the resident will then come to an agreement with the primary care team on the best course of action

\section{Collaborator}

Residents are expected to collaborate with health care teams and allied health staff throughout this rotation. This will be emphasized through multiple areas

- Recognize their limitations when scans are challenging or inconclusive, and seek consultation from medical experts in this field and other disciplines where appropriate

- Learn how to advise other physicians in an oral format on ultrasound findings in which the resident has developed expertise

- Foster healthy team relationships with allied health staff in situations where patient management is altered or follow-up testing is needed

\section{Professional}

Residents must:

- Always demonstrate respectful and compassionate behaviour toward patients, their families, and other health care providers

- Prioritize clinically indicated ultrasound examinations, where intervention may be required, over educational scans

- Remain calm and organized in stressful or emergency situations

- When appropriate, participate through attendance, interaction, and presentation at educational sessions including departmental and resident rounds

Assessment of competency remains a challenge ${ }^{31}$ and mostly relies on subjective observation and checklists. Point-of-care ultrasound is not yet recognized as a milestone in anesthesiology training in the USA by the ACGME. The Royal College of Physicians and Surgeon's of Canada subspecialty committee for anesthesiology has defined bedside ultrasound in hemodynamic management as a new entrusted professional activity within the new Competency by Design (CBD) residency training platform. The University of Ottawa has recently proposed an integrated anesthesia POCUS curriculum that includes assessments and milestones. This may be a pilot project on which to build a National Curriculum. ${ }^{32}$ 
Table 4 Milestones in core curriculum

\begin{tabular}{|c|c|c|c|c|c|c|}
\hline Modality & Milestone \#1 & Milestone \#1 & Milestone \#2 & Milestone \#3 & Milestone \#4 & Milestone \#5 \\
\hline Cardiac & $\begin{array}{l}\text { Demonstration of: } \\
\text { adequate probe } \\
\text { selection and } \\
\text { manipulation } \\
\text { US machine adjustment } \\
\text { of basic settings }\end{array}$ & $\begin{array}{l}\text { Acquisition of basic } \\
\text { views in healthy } \\
\text { volunteer and } \\
\text { correlation with } \\
\text { anatomical } \\
\text { structures }\end{array}$ & $\begin{array}{l}\text { Acquisition of } \\
\text { five basic } \\
\text { views in } \\
\text { intubated } \\
\text { ventilated } \\
\text { patient }\end{array}$ & $\begin{array}{l}\text { Completion of } \\
\text { portfolio } \\
\text { including } \\
\text { normal and } \\
\text { pathologic } \\
\text { scans }\end{array}$ & $\begin{array}{l}\text { Integration of US in the } \\
\text { clinical diagnosis of right } \\
\text { and left ventricular } \\
\text { dysfunction, } \\
\text { hypovolemia, and } \\
\text { vasodilatation }\end{array}$ & $\begin{array}{l}\text { Integration of } \\
\text { US in the } \\
\text { clinical } \\
\text { diagnosis of } \\
\text { tamponade }\end{array}$ \\
\hline Lung & $\begin{array}{l}\text { (gain, image depth, } \\
\text { focus, image freeze, } \\
\text { and archiving) }\end{array}$ & & $\begin{array}{l}\text { Acquisition of } \\
\text { basic view } \\
\text { in intubated } \\
\text { ventilated } \\
\text { patient }\end{array}$ & & $\begin{array}{l}\text { Integration of US in the } \\
\text { clinical diagnosis of } \\
\text { pneumothorax }\end{array}$ & $\begin{array}{l}\text { Integration of } \\
\text { US in the } \\
\text { clinical } \\
\text { diagnosis of } \\
\text { pleural } \\
\text { effusion }\end{array}$ \\
\hline $\begin{array}{l}\text { Focused } \\
\text { assessment } \\
\text { sonography } \\
\text { in trauma }\end{array}$ & & & & & $\begin{array}{l}\text { Integration of US in the } \\
\text { clinical diagnosis of fee } \\
\text { peritoneal fluid }\end{array}$ & \\
\hline
\end{tabular}

$\mathrm{US}=$ ultrasound

Once defined, the assessment of POCUS-specific competencies remains problematic. There is little doubt that direct observation of performance on real patients is the preferred means of assessment; however, the lack of trained faculty mentioned above limits opportunity for such evaluations. Further limitations to one-on-one bedside teaching include ethical considerations and inconsistent patient pathology. Assuming one can accurately assess the technical and cognitive competencies of POCUS, there is no consensus among authors on what constitutes the minimum numbers of scans for each application. While for some of the applications, authors have assessed the learning curve to achieve competency, for most the number suggested by many guidelines and consensus documents is based on expert opinion without solid evidence.

To obviate some of these limitations, the Objective Structured Clinical Examination (OSCE) method has been proposed for POCUS training. ${ }^{33}$ Image acquisition skills shown in model patients-often young, healthy, and compliant-may not be easily reproduced in the less controlled population in the perioperative period. While modern simulators are producing increasingly more realistic pathologic representations, the variety of pathology may still be limited and often artificial. Specific rapid assessment tools have been proposed by other specialties ${ }^{34}$ but their validity for anesthesia and the perioperative setting remains unknown. Definition of maintenance of competency remains a challenge as it has rarely been addressed in current literature.

\section{Future directions}

In the CBD framework, POCUS objectives need to be integrated in a specific CanMEDS format. Point-of-care ultrasound-specific training milestones and entrustable professional activities will need to be defined to harmonize a new curriculum with the Royal College of Physicians and Surgeons of Canada's Competency by Design framework (http://www.royalcollege.ca/rcsite/cbd/ cbd-assessment-e). Use of this framework raises several challenging questions. How will programs define specific scenarios and matching skills that provide clearly evaluable milestones? How will non-technical skills such as reporting (Communicator) and continuous quality improvement (Health Advocate) be assessed and mapped to CanMEDS 2015 roles? (Table 3 ).

A first step in the development of a Canadian POCUS curriculum is the clear identification of basic and advanced applications. A common curriculum for these basic skills, based on best evidence and comparable guidance from other agencies, is required if these skills are made a mandatory element of Canadian anesthesia training; POCUS training should include basic and advanced applications (Table 4).

Introduction to the general principles of ultrasound physics, probe selection, image orientation, and optimization should constitute the foundation of the POCUS discipline and be shared with other operative ultrasound-guided applications such as line insertion and regional anesthetic techniques, which we believe should be treated separately from POCUS. Core POCUS competence should include broadly accepted basic modalities currently supported by strong scientific evidence such as focused cardiac ultrasound, ${ }^{6}$ lung ultrasound, ${ }^{7}$ and FAST. ${ }^{8}$

Basic POCUS should aim at providing qualitative assessment and answer binary questions as part of clinical decision-making. Applications of each modality should be limited to the use of basic two-dimensional 
imaging, achievable with any ultrasound system. They must include acquisition of basic views and aim at identifying specific conditions such as ventricular failure, hypovolemia, tamponade, pneumothorax, pleural effusion, and intra-abdominal free fluid.

Each POCUS modality should constitute a core curriculum module built on the I-AIM framework. ${ }^{35,36}$ Self-directed learning though online modules or other reading material and logged simulation training (whenever available) should precede hands-on training on volunteers. Image interpretation should be acquired though supervised case discussions and self-directed online case review. Milestones for core module completion include image acquisition on healthy volunteers and completion of a basic image acquisition portfolio. The extent of the portfolio should be defined based on current evidence and other societies' guidelines. The trainees must complete an image interpretation log whose extent is to be defined and include normal and pathologic studies of varying image quality. Image acquisition skills should be assessed by direct observation on volunteers and review of the portfolio.

Core curriculum is to be delivered early during the residency training to allow enough time for integration into clinical decision-making during transition to practice.

This phase would focus on the daily application on patients. Final skills assessment should thus be based on demonstration of competency in all defined basic clinical scenarios and achievement of CanMEDS roles including POCUS training.

Definition of mentors and supervisors would initially have to rely on individual experience and availability at each centre; however, definition of scholar competencies has to be defined based on a specific training pathway in the future.

\section{Conclusions}

Despite an increase in the introduction of POCUS curricula in anesthesia and perioperative medicine, significant variability exists among curricula. This variability is compounded by a lack of national standards for POCUS competencies for the perioperative setting. The development of a national core POCUS curriculum for perioperative POCUS for anesthesiologists is necessary to assure standard of practice as it is perceived as a limiting factor to the development of perioperative POCUS practice despite a growing body of effective applications in perioperative medicine. Definition of scope of practice of POCUS in the perioperative context is the first step to development of a common curriculum. Generic guidelines and POCUS learning frameworks are available to guide curriculum development; however, definition of training goals has to be adapted to individual national residency curricula. They should also incorporate specific guides on how to train and establish competency for practicing anesthesiologists.

To rapidly advance training in and use of POCUS in perioperative care, one could look to the advancement of intraoperative transesophageal echocardiography where practice and training are clearly defined by guidelines by joined anesthesiologists' and echocardiographers' societies. A similar opportunity might be found among specialities who share anesthesiologists' interest in trauma and critical care. Finally, new curricula should incorporate newer teaching approaches including simulation and online learning. Assessment and maintenance of competency remain a challenge and the methods used may be different when assessing anesthesia trainees compared with staff anesthesiologists.

\section{References}

1. Adler AC, Greeley WJ, Conlin F, Feldman JM. Perioperative anesthesiology ultrasonographic evaluation (PAUSE): a guided approach to perioperative bedside ultrasound. J Cardiothorac Vasc Anesth 2016; 30: 521-9.

2. Botker MT, Vang ML, Grofte T, Sloth E, Frederiksen CA. Routine pre-operative focused ultrasonography by anesthesiologists in patients undergoing urgent surgical procedures. Acta Anaesthesiol Scand 2014; 58: 807-14.

3. Das SK, Choupoo NS, Haldar R, Lahkar A. Transtracheal ultrasound for verification of endotracheal tube placement: a systematic review and meta-analysis. Can J Anesth 2015; 62: 413-23.

4. Perlas A, Mitsakakis N, Liu L, et al. Validation of a mathematical model for ultrasound assessment of gastric volume by gastroscopic examination. Anesth Analg 2013; 116: 357-63.

5. Ursprung E, Oren-Grinberg A. Point-of-care ultrasound in the perioperative period. Int Anesthesiol Clin 2016; 54: 1-21.

6. Via G, Hussain A, Wells $M$, et al. International evidence-based recommendations for focused cardiac ultrasound. J Am Soc Echocardiogr 2014; 27: 683.e1-33.

7. Volpicelli $G$, Elbarbary $M$, Blaivas $M$, et al. International evidence-based recommendations for point-of-care lung ultrasound. Intensive Care Med 2012; 38: 577-91.

8. Bahner D, Blaivas $M$, Cohen HL, et al. AIUM practice guideline for the performance of the focused assessment with sonography for trauma (FAST) examination. J Ultrasound Med 2008; 27: 313-8.

9. Chan VW, Perlas A, Rawson R, Odukoya O. Ultrasound-guided supraclavicular brachial plexus block. Anesth Analg 2003; 97 : 1514-7.

10. Asheim P, Mostad U, Aadahl P. Ultrasound-guided central venous cannulation in infants and children. Acta Anaesthesiol Scand 2002; 46: 390-2.

11. Beique F, Ali M, Hynes $M$, et al. Canadian guidelines for training in adult perioperative transesophageal echocardiography. Recommendations of the Cardiovascular Section of the Canadian Anesthesiologists' Society and the Canadian Society of Echocardiography. Can. J Anesth 2006; 53: 1044-60.

12. Hahn RT, Abraham T, Adams MS, et al. Guidelines for performing a comprehensive transesophageal echocardiographic 
examination: recommendations from the American Society of Echocardiography and the Society of Cardiovascular Anesthesiologists. J Am Soc Echocardiogr 2013; 26: 921-64.

13. Reeves ST, Finley AC, Skubas NJ, et al. Basic perioperative transesophageal echocardiography examination: a consensus statement of the American Society of Echocardiography and the Society of Cardiovascular Anesthesiologists. Anesth Analg 2013; 117: 543-58

14. Jasudavisius A, Arellano R, Martin J, McConnell B, Bainbridge $D$. A systematic review of transthoracic and transesophageal echocardiography in non-cardiac surgery: implications for pointof-care ultrasound education in the operating room. Can J Anesth 2016; 63: 480-7.

15. Mok D, Schwarz SK, Rondi K. Point-of-care ultrasonography in Canadian anesthesiology residency programs: a national survey of program directors. Can J Anesth 2017; 64: 1023-6.

16. Mahmood F, Matyal R, Skubas N, et al. Perioperative ultrasound training in anesthesiology: a call to action. Anesth Analg 2016; 122: $1794-804$.

17. Atkinson P, Bowra J, Lambert M, Lamprecht H, Noble V, Jarman $B$. International Federation for Emergency Medicine point of care ultrasound curriculum. CJEM 2015; 17: 161-70.

18. Arntfield $R$, Millington $S$, Ainsworth $C$, et al. Canadian recommendations for critical care ultrasound training and competency. Can Respir J 2014; 21: 341-5.

19. Mayo PH, Beaulieu Y, Doelken P, et al. American College of Chest Physicians/La Société de Réanimation de Langue Francaise statement on competence in critical care ultrasonography. Chest 2009; 135: 1050-60.

20. Expert Round Table on Ultrasound in ICU. International expert statement on training standards for critical care ultrasonography. Intensive Care Med 2011; 37: 1077-83.

21. Association of Anaesthetists of Great Britain \& Ireland. Ultrasound in Anaesthesia and Intensive Care: A Guide to Training, 2011. Available from URL: http://www.aagbi.org/ publications/publications-guidelines/ultrasound-anaesthesia-andintensive-care-guide-training (accessed December 2017).

22. Ramsingh D, Rinehart J, Kain Z, et al. Impact assessment of perioperative point-of-care ultrasound training on anesthesiology residents. Anesthesiology 2015; 123: 670-82.

23. Mitchell JD, Montealegre-Gallegos M, Mahmood F, et al. Multimodal perioperative ultrasound course for interns allows for enhanced acquisition and retention of skills and knowledge. A A Case Rep 2015; 5: 119-23.

24. Tanzola RC, Walsh S, Hopman WM, Sydor D, Arellano R, Allard $R V$. Brief report: focused transthoracic echocardiography training in a cohort of Canadian anesthesiology residents: a pilot study. Can J Anesth 2013; 60: 32-7.
25. Arntfield R, Pace J, McLeod S, Granton J, Hegazy A, Lingard L. Focused transesophageal echocardiography for emergency physicians-description and results from simulation training of a structured four-view examination. Crit Ultrasound J 2015; 7: 27.

26. Jensen JK, Dyre L, Jorgensen ME, Andreasen LA, Tolsgaard $M G$. Collecting validity evidence for simulation-based assessment of point-of-care ultrasound skills. J Ultrasound Med 2017; 36: 2475-83.

27. Jerath A, Vegas A, Meineri $M$, et al. An interactive online 3D model of the heart assists in learning standard transesophageal echocardiography views. Can J Anesth 2011; 58: 14-21.

28. Vegas A, Meineri M, Jerath A, Corrin M, Silversides C, Tait G. Impact of online transesophageal echocardiographic simulation on learning to navigate the 20 standard views. J Cardiothorac Vasc Anesth 2013; 27: 531-5.

29. Conlin F, Roy Connelly N, Raghunathan $K$, Friderici J, Schwabauer A. Focused transthoracic cardiac ultrasound: a survey of training practices. J Cardiothorac Vasc Anesth 2016; 30: 102-6.

30. Botker MT, Vang ML, Grofte T, Kirkegaard H, Frederiksen CA, Sloth $E$. Implementing point-of-care ultrasonography of the heart and lungs in an anesthesia department. Acta Anaesthesiol Scand 2017; 61: 156-65.

31. Poelaert J, Mayo P. Education and evaluation of knowledge and skills in echocardiography: how should we organize? Intensive Care Med 2007; 33: 1684-6.

32. McCormick TJ, Mir Ghassemi A, Fayad A, et al. Designing a point of care ultrasound (POCUS) curriculum for competency by design anesthesiology residency programs. Can J Anesth 2017; 64(Supplement): 280128 (abstract).

33. Rebel A, Srour H, DiLorenzo A, et al. Ultrasound skill and application of knowledge assessment using an innovative OSCE competition-based simulation approach. J Educ Perioper Med 2016; 18: E404.

34. Millington SJ, Arntfield RT, Hewak $M$, et al. The rapid assessment of competency in echocardiography scale: validation of a tool for point-of-care ultrasound. J Ultrasound Med 2016; 35: 1457-63.

35. Kruisselbrink R, Chan V, Cibinel GA, Abrahamson S, Goffi A. IAIM (indication, acquisition, interpretation, medical decisionmaking) framework for point of care lung ultrasound. Anesthesiology 2017; 127: 568-82.

36. Perlas A, Van de Putte P, Van Houwe P, Chan VW. I-AIM framework for point-of-care gastric ultrasound. $\mathrm{Br} \mathrm{J}$ Anaesth 2016; 116: 7-11. 